\title{
Cutting Temperature investigation when Heavy Milling Welded Aluminum-Thin- Walled Hollow Structure
}

\author{
Y. F. Ge $e^{1, a^{*}}$, J. M. Hou ${ }^{1, b}$ X. L. Jia ${ }^{1, c}$ and C. Liu $u^{1, d}$ \\ ${ }^{1}$ School of Mechanical Engineering, Nanjing Institute of Technology, Nanjing 211167, China

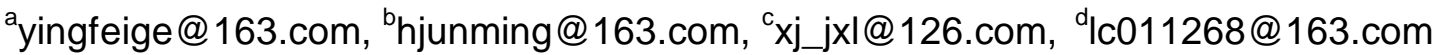

Keywords: Aluminum alloy, Welded part, Thin-walled hollow structure, Heavy milling, Cutting temperature

Abstract. Carbide tools were used to investigate the cutting temperature when heavy milling 6N01-T5 aluminum thin-walled hollow W-shape structures. The results showed that the value of cutting temperature at the area of weld seam or the intersectant ribbed slab was $40-60 \%$ times higher than that of cutting the single ribbed slab while cutting temperature for the weld seam was $20 \%$ times higher than that of the intersectant ribbed slab where severe adhesive wear often took place on the tool. The significance order of the cutting parameters was radial depth of cut, axial depth of cut, feed rate, spindle speed and increasing the spindle speed reduced the cutting temperature. The value of cutting temperature for the none wave edge tool was $40-80^{\circ} \mathrm{C}$ higher than that for the wave edge tool while the value of cutting temperature for the rake wave edge tool was $40^{\circ} \mathrm{C}$ bigger than that for the flank wave edge tool. However, the wave edge tool was more inclined to taking place severe adhesive wear which attributes to the coarser tool face. The cutting temperature of CPMJI was $80^{\circ} \mathrm{C}$ lower than that of dry cutting and the situation of severe adhesive wear seldom took place when CPMJI was used compared to dry cutting and cryogenic wind cooling.

\section{Introduction}

Due to the high ductility and sticky nature, high chemical activity of the aluminum alloy, there are many machining problems such as tool irregular wear, sever adhesion on the tool face and burrs and marks of pressing/extrusion on the machined surface [1-2]. These problems have a great influence on the efficiency, quality and cost when machining this kind of material. Heavy cutting method was generally used when machining aluminum structures so as to improve the efficiency [3], which causes a high level of cutting force and cutting temperature that leads to the generation of obvious build-up-edge or the melt of the aluminum alloy [3-4]. In this case, a effective cooling method is needed to reduce the cutting temperature. However, the regular cooling method which often uses the regular coolant liquid with large rate of flow may cause the oxidization on the surface of the aluminum alloy and the contamination by the cutting oil which has a detrimental effect on the subsequent welding process of the parts [4]. The expensive special coolant is often applied when heavy machining aluminum alloy structures, which in turn greatly increases the machining cost [5].

In the recent ten years, a quantity of researches have been done on the high/ultra-high speed machining on aluminum alloys but little attention has been given to the study on the heavy cutting frames or thin-walled structures under the medium or low cutting speed [6-13]. For these special structures, a combination cutting parameters of very big axial and radial depth of cut, very high feed rate was often selected when machining [7-8]. The common characters of these special structures are the low stiffness and the high value of cutting temperature, force and vibration [10]. Therefore, a poor machining quality is often obtained and the tool wear rate and the cost of cutting tool are high when compared to the machining of aluminum sheet [11].

Cutting temperature has an intimate relationship with machining surface quality and tool wear. The controlling or reducing of cutting temperature when heavy cutting low stiffness structures is very important because the machining deformation and the tool wear rate will be greatly reduced. In this investigation, a 6N01-T5 aluminum thin-walled hollow W-shape structure was selected as the 
workpiece and several kinds of commercial cutting tools were used to investigate the cutting temperature and these influence factors under the heavy milling condition.

\section{Experimental Work}

Materials and Machine Tools. Sample of dimensions 600 × 500 × $60 \mathrm{~mm}$ of 6N01-T5 aluminum thin-walled hollow W-shape structure was selected for the experiment. The thickness of the single ribbed slab (aluminum alloy sheet) is $2.5-3 \mathrm{~mm}$. The workpiece sample was fixed on the worktable of machine tool with four clamps (Fig. 1). The composition and physical properties of 6N01-T5 aluminum alloy are given in Table 1 and Table 2, respectively. The cutting tools used were carbide cutters DIJET $^{\mathrm{TM}}, \mathrm{SECO}^{\mathrm{TM}}, \mathrm{SHANYING}{ }^{\mathrm{TM}}$ ) with a diameter of $20 \mathrm{~mm}$. Tool materials and the specifications are tabulated in Table 3. All the milling tests were conducted on the DMG DMC70V hi-dyn milling center.

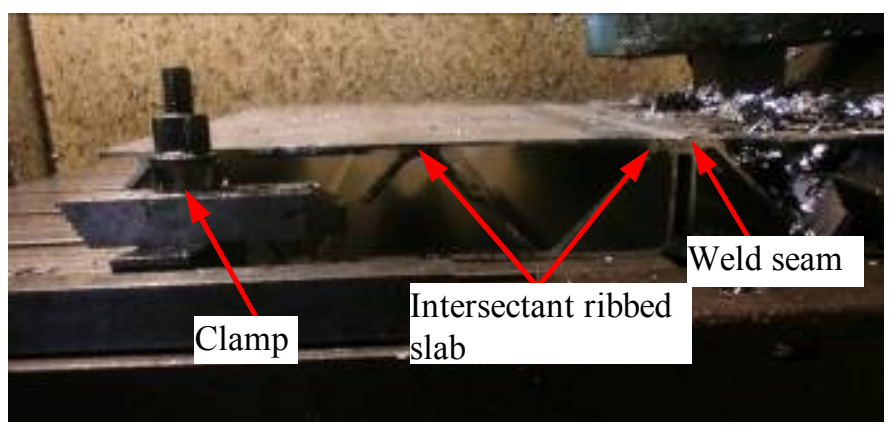

Fig. 1 Workpiece for the cutting temperature tests

Table 1 Main chemical composition of 6N01-T5 (Wt. \%)

\begin{tabular}{cccccccc}
\hline $\mathrm{Mg}$ & $\mathrm{Mn}$ & $\mathrm{Cr}$ & $\mathrm{Cu}$ & $\mathrm{Fe}$ & $\mathrm{Si}$ & $\mathrm{Zn}$ & $\mathrm{Al}$ \\
\hline $0.4-0.8$ & 0.5 & 0.3 & 0.35 & 0.35 & $0.4-0.9$ & 0.25 & Balance \\
\hline
\end{tabular}

Table 2 Physical and mechanical properties of Stellite 6 alloy at room temperature

\begin{tabular}{cccc}
\hline $\begin{array}{c}\text { Ultimate Tensile Strength } \\
{\left[\mathrm{kgf} / \mathrm{mm}^{2}\right]}\end{array}$ & $\begin{array}{c}\text { Yield Strength } \\
{\left[\mathrm{kgf} / \mathrm{mm}^{2}\right]}\end{array}$ & Elongation Ratio [\%] & Hardness [HV] \\
\hline $25.0-29.5$ & $21.0-27.0$ & $8-11$ & $80-95$ \\
\hline
\end{tabular}

Table 3 Details of the cutting tools and the cutting conditions

\begin{tabular}{cccccc}
\hline Tool supplier & $\begin{array}{c}\text { Rake } \\
\text { angle }\left[{ }^{\circ}\right]\end{array}$ & $\begin{array}{c}\text { Flank } \\
\text { angle }\left[{ }^{\circ}\right]\end{array}$ & $\begin{array}{c}\text { Helix } \\
\text { angle }\left[{ }^{\circ}\right]\end{array}$ & Flutes & $\begin{array}{c}\text { Cooling } \\
\text { condition }\end{array}$ \\
\hline DIJET & 20 & 12 & 45 & 2 & Dry \\
\hline DIJET & 20 & 12 & 45 & 2 & $\begin{array}{c}\text { cryogenic } \\
\text { wind }\end{array}$ \\
\hline DIJET & 20 & 12 & 45 & 2 & CPMJI \\
\hline SECO & 7 & 10 & 40 & 2 & CPMJI \\
\hline SHANGYING (none wave edge) & 0 & 12 & 25 & 3 & Dry \\
\hline SHANGYING (flank wave edge) & 0 & 12 & 25 & 3 & Dry \\
\hline SHANGYING (rake wave edge) & 0 & 12 & 25 & 3 & Dry \\
\hline
\end{tabular}

Experimental Scheme. The cooling system is shown in Fig. 2. As observed, the condition of cryogenic pneumatic mist jet impinging cooling (CPMJ) can be obtained when all the valves of the cooling system are open. The cryogenic wind can be acquired when only using the compressed air and the cooling gun. Hence, the effect of cooling condition (dry, cryogenic wind and CPMJI) on the cutting vibration can be compared (Table 3 ). The effect of cutting tool's edge shape on the cutting vibration also investigated in this study. 
Cutting temperature was measured with the Optris ${ }^{\mathrm{TM}}$ CT 8081137 infrared temperature measurement instrument. The emissivity of the was set at 0.105 after calibrated. The experimental work for the cutting vibration and cutting temperature measurement is shown in Fig. 3.

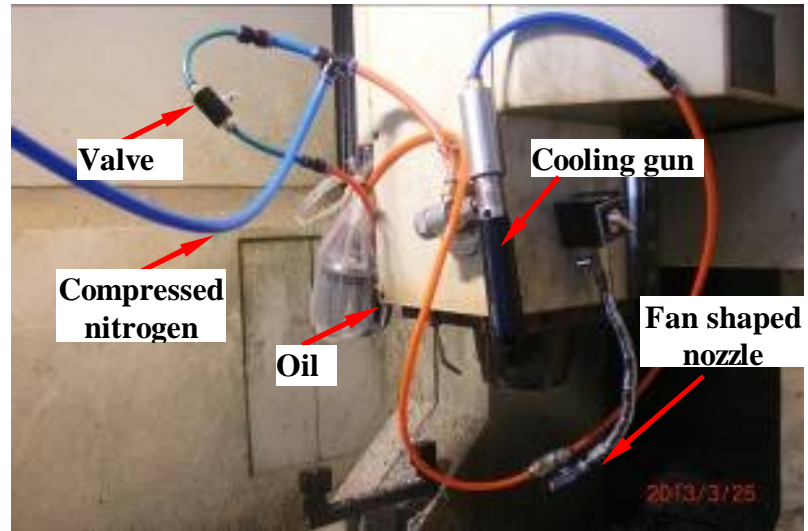

Fig. 2 The cryogenic pneumatic mist jet impinging cooling system

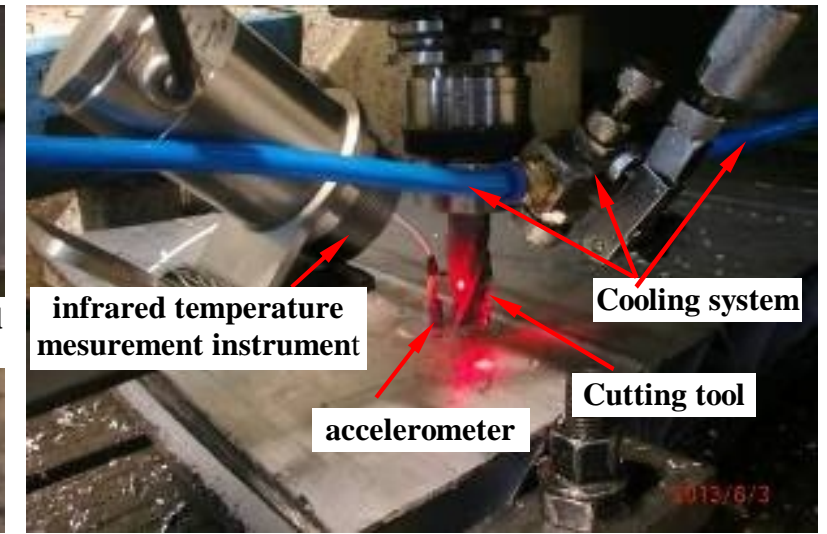

Fig.3 The experimental work for the cutting vibration and cutting temperature measurement

The Taguchi method was used in the experiments design of cutting temperature study (Table 4). The orthogonal array selected was the $L_{9}\left(4^{3}\right)$ corresponding to 4 parameters with 3 levels each as shown in Table 5. The outputs studied were cutting temperature $(\theta)$. The treatment of the experimental results was based on the analysis of signal-to-noise $(\mathrm{S} / \mathrm{N})$ ratio.

Table 4 Cutting parameters and their levels (SECO, new tool, CPMJ)

\begin{tabular}{cccccc}
\hline Symbol & Cutting parameters & Unit & Level 1 & Level 2 & Level 3 \\
\hline A & Spindle speed & rev/min & 8000 & 5000 & 3000 \\
B & Feed rate & mm/tooth & 0.2 & 0.1 & 0.05 \\
C & Axial depth of cut & mm & 20 & 10 & 5 \\
D & Radial depth of cut & mm & 5 & 10 & 20 \\
\hline \multicolumn{7}{c}{ Table 5 Three-factor three-level $\left(\mathrm{L}_{9}\right)$ Taguchi orthogonal table } \\
\hline Test & Spindle speed $N$ & Feed rate $f_{z}$ & Axial depth of cut & Radial depth of cut \\
number & (rev/min) & (mm/tooth) & $a_{p}($ mm) & $a_{w}(\mathrm{~mm})$ \\
\hline No.1 & 8000 & 0.2 & 20 & 5 \\
No.2 & 8000 & 0.1 & 10 & 10 \\
No.3 & 8000 & 0.05 & 5 & 20 \\
No.4 & 5000 & 0.1 & 20 & 20 \\
No.5 & 5000 & 0.05 & 10 & 5 \\
No.6 & 5000 & 0.2 & 5 & 10 \\
No.7 & 3000 & 0.05 & 20 & 10 \\
No.8 & 3000 & 0.2 & 10 & 20 \\
No.9 & 3000 & 0.1 & 5 & 5 \\
\hline
\end{tabular}

The goal of the study is to optimize the milling parameters to get lower cutting temperature so as to reduce the chance of severe adhesive wear on the tool. Thus, the observed values of cutting temperature were set to minimum. That means that the objective function, $\mathrm{S} / \mathrm{N}$ ratio, is calculated based on the-smaller-the-better characteristic, which can be calculated as:

$$
\frac{S}{N}=10 \log _{10}\left(\frac{1}{n} \sum_{i=1}^{n} y_{i}^{2}\right)
$$


where $y_{i}$ is the observed data and $n$ is the number of observations.

\section{Results and Discussion}

Analysis on the Typical Cutting Temperature Signal. As can be observed from Fig. 4, the cutting temperature increased dramatically when the tool cut at the area of weld seam or the intersectant ribbed slab, which is due to the fact that the actual axial depth of cut increases abruptly (by $100 \%-600 \%$ ) when the tool cuts at these areas. As shown in Fig.5. the value of cutting temperature at the area of weld seam or the intersectant ribbed slab was $40-60 \%$ times higher than that of cutting the single ribbed slab (aluminum alloy sheet). It also can be observed from Fig. 4 that the cutting temperature for the weld seam was $20 \%$ times higher than that of the intersectant ribbed slab. Therefore, the aluminum alloy became more soft and more easily stick to the tool face. When a more aggressive cutting parameters or a worn tool were used, severe adhesive wear would take place on the tool.

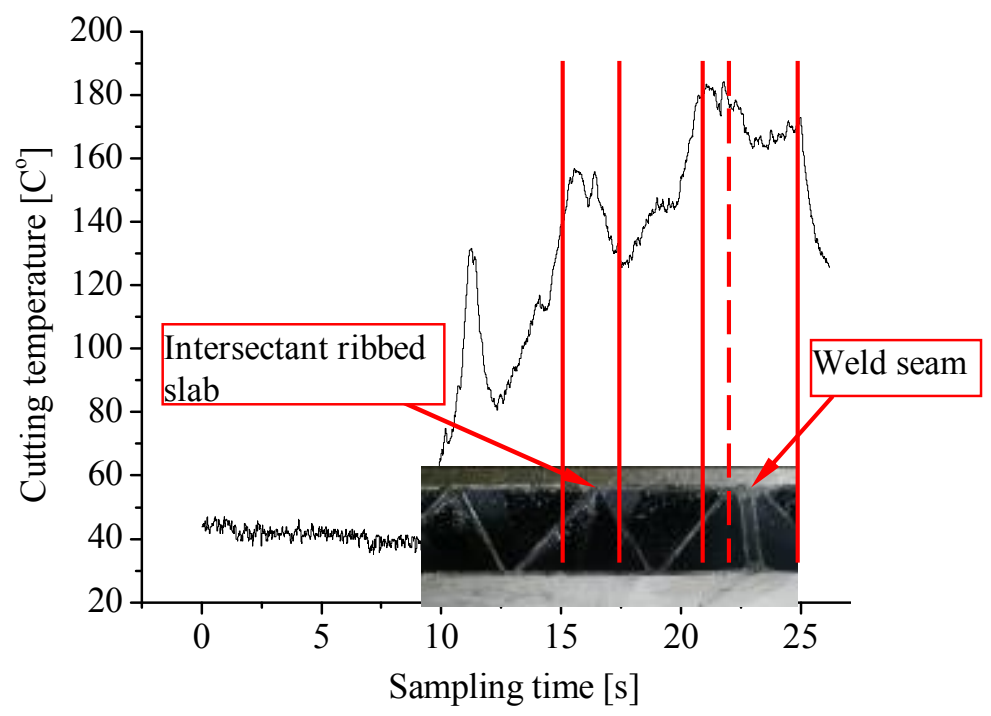

Fig. 4 The typical cutting temperature signal for the welded aluminum-thin-walled hollow structure (DIJET new tool, $N=5000 \mathrm{rev} / \mathrm{min}, f_{z}=0.1 \mathrm{~mm} /$ tooth, $a_{p}=20 \mathrm{~mm}, a_{w}=20 \mathrm{~mm}$, Dry cutting)

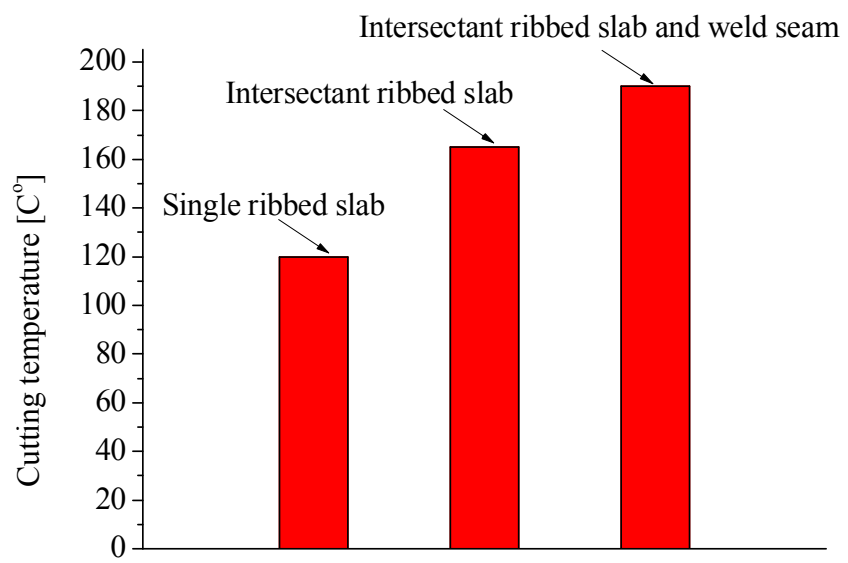

Fig. 5 Cutting temperature comparison when the tool cut different structure of the workpiece in Fig.4

Influence of Cutting Parameters on the Cutting Temperature (Analysis of the S/N Ratio). Table 6 shows the experimental results for cutting temperature and the corresponding $\mathrm{S} / \mathrm{N}$ ratio. The mean $\mathrm{S} / \mathrm{N}$ ratio for each level of the four cutting parameters is summarized and called the $\mathrm{S} / \mathrm{N}$ response table for cutting temperature (Table 7). In addition, the different values of $\mathrm{S} / \mathrm{N}$ ratio between maximum and 
minimum for the three levels of each factor are also calculated and listed in Table 7. Fig. 6 shows the $\mathrm{S} / \mathrm{N}$ response graph for cutting temperature. According to Table 7 and Fig. 6, factor D (radial depth of cut) has the highest difference between maximum and minimum values 3.97 and this is followed by factors $\mathrm{C}$ (axial depth of cut) and B (feed rate) which have the difference values 1.35 and 0.59 , respectively. Factor A (spindle speed) has the lowest difference value 0.24 . Thus, it can be concluded that the significance order of the influence factors is radial depth of cut, axial depth of cut, feed rate, spindle speed based on the Taguchi prediction that the larger different between value of $\mathrm{S} / \mathrm{N}$ ratio will have a more significant effect on cutting temperature $(\theta)$. It is observed in Fig. 6 and Table 7 that level 2 of A factor (spindle speed), level 3 of B factor (feed rate), level 3 of C factor (axial depth of cut) and level 1 of $\mathrm{D}$ factor (radial depth of cut) are lower. Consequently, the optimum cutting conditions determined under the same conditions for the cutting temperature experiments to be conducted will be $5000 \mathrm{rev} / \mathrm{min}$ for the spindle speed, $0.05 \mathrm{~mm} /$ tooth for the feed rate, $5 \mathrm{~mm}$ for the axial depth of cut and $5 \mathrm{~mm}$ for the radial depth of cut.

Table 6 Experimental results for cutting temperature and $\mathrm{S} / \mathrm{N}$ ratio

\begin{tabular}{cccccccccc}
\hline Test number & No.1 & No.2 & No.3 & No.4 & No.5 & No.6 & No.7 & No.8 & No.9 \\
$\begin{array}{c}\text { Cutting temperature } \\
\theta /\left({ }^{\circ} \mathrm{C}\right)\end{array}$ & 154.0 & 188.7 & 194.2 & 224.7 & 136.7 & 178.5 & 199.6 & 237.9 & 125.2 \\
S/N ratio /dB & 43.75 & 45.51 & 45.76 & 47.03 & 42.71 & 45.03 & 46.0 & 47.52 & 41.95 \\
\hline
\end{tabular}

Table $7 \mathrm{~S} / \mathrm{N}$ response table for cutting temperature

\begin{tabular}{cccccc}
\hline \multirow{2}{*}{ Symbol } & \multirow{2}{*}{ Cutting parameters } & \multicolumn{4}{c}{ Mean S/N ratio(dB) } \\
\cline { 3 - 5 } & & Level 1 & Level 2 & Level 3 & Max-Min \\
\hline A & Spindle speed & 45.01 & 44.92 & 45.16 & 0.24 \\
B & Feed rate & 45.43 & 44.83 & 44.82 & 0.59 \\
C & Axial depth of cut & 45.59 & 45.25 & 44.24 & 1.35 \\
D & Radial depth of cut & 42.80 & 45.51 & 46.77 & 3.97 \\
\hline
\end{tabular}

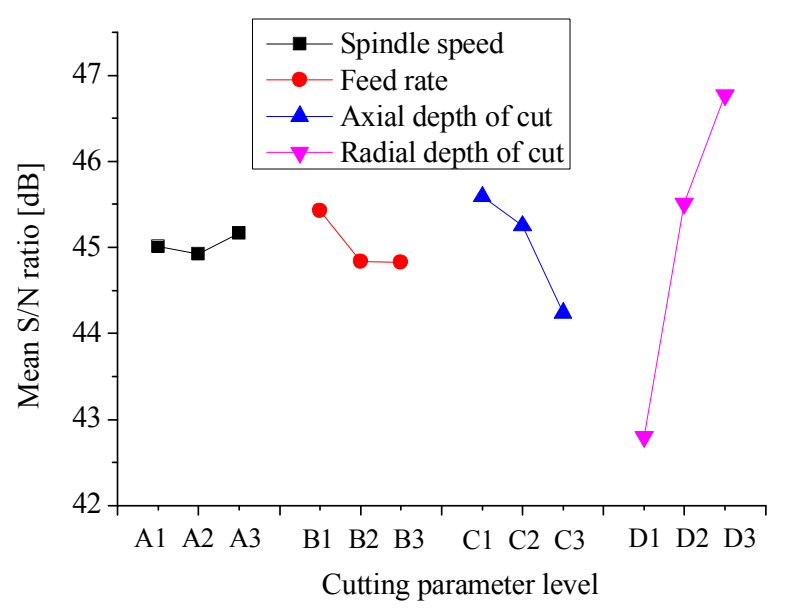

Fig. $6 \mathrm{~S} / \mathrm{N}$ response graph for cutting temperature

The non-linear multiple regression analysis method has been deployed to analyze the cutting temperature in the form of empirical equation. Based on the datum from Table 6, the empirical equation of cutting temperature obtained is as follows:

$$
\theta=e^{4.02} n^{-0.02} v_{f}{ }^{0.05} a_{p}{ }^{0.11} a_{w}{ }^{0.28}, \mathrm{R}^{2}=0.98, \mathrm{~F}=62.7
$$


It is observed from Fig. 6 and Eq. (2) that spindle speed and feed rate have a little effect on the cutting temperature and that increasing the spindle speed will reduce the cutting temperature.

Influence of Tool Edge Shape on the Cutting Temperature. As shown in Fig. 7, the value of cutting temperature for the none wave edge tool is $40-80^{\circ} \mathrm{C}$ higher than that for the wave edge tool. As for the wave edge tools, the value of cutting temperature for the rake wave edge tool is $40^{\circ} \mathrm{C}$ bigger than that for the flank wave edge tool. Although the value of cutting temperature for the wave edge tool is lower than that for the none wave edge tool, the former is more inclined to taking place severe adhesive wear which attributes to the coarser tool face of the wave edge tool.

Influence of Cooling Condition on Cutting Temperature. As shown in Fig. 8, for the three kinds of cooling conditions used, the use of CPMJI produced the lowest value of cutting temperature while dry cutting produced the highest value of cutting temperature. Fig. 8 also shows that the cutting temperature of CPMJI was $80^{\circ} \mathrm{C}$ lower than that of dry cutting, which indicates that the cooling effect of the new type of CPMJI is significant. It was found that the situation of severe adhesive wear seldom took place when CPMJI was used compared to dry cutting and cryogenic wind cooling.

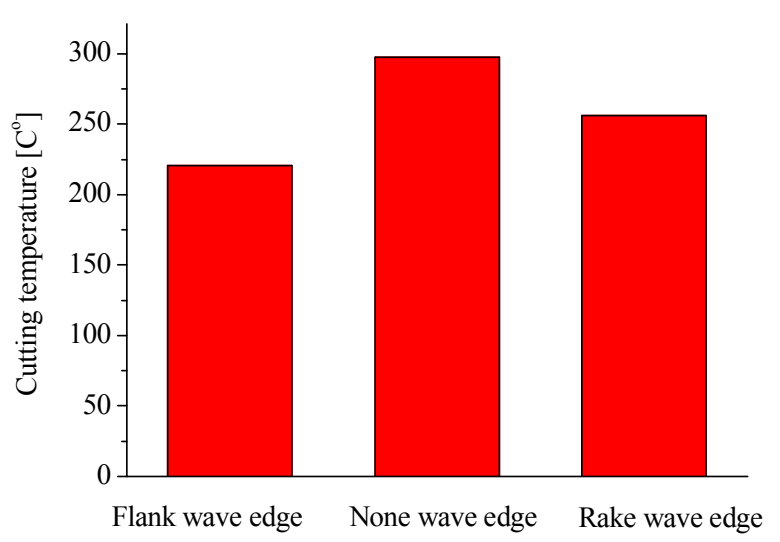

Fig. 7 The effect of tool edge shape on the cutting temperature (SHANYING, Dry cutting, $n=5000 \mathrm{rev} / \mathrm{min}, f_{z}=0.1 \mathrm{~mm} /$ tooth , $\left.a_{p}=20 \mathrm{~mm}, a_{w}=20 \mathrm{~mm}\right)$

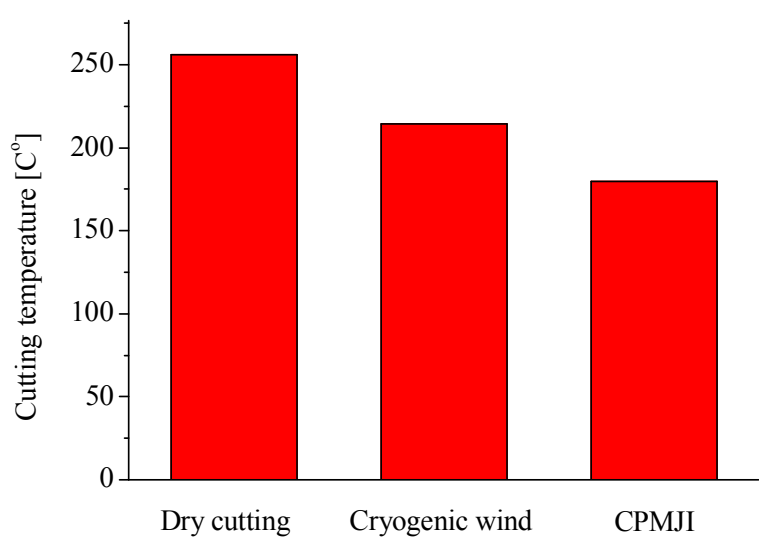

Fig. 8 The effect of cooling condition on the cutting temperature (DIJET, $n=5000 \mathrm{rev} / \mathrm{min}$, $f_{z}=0.1 \mathrm{~mm} /$ tooth,$\left.a_{p}=20 \mathrm{~mm}\right)$ ,$\left.a_{w}=20 \mathrm{~mm}\right)$

\section{Conclusions}

(1) The value of cutting temperature at the area of weld seam or the intersectant ribbed slab was $40-60 \%$ times higher than that of cutting the single ribbed slab (aluminum alloy sheet) while cutting temperature for the weld seam was $20 \%$ times higher than that of the intersectant ribbed slab where severe adhesive wear often took place on the tool.

(2) The significance order of the cutting parameters was radial depth of cut, axial depth of cut, feed rate, spindle speed and increasing the spindle speed reduced the cutting temperature. The optimum cutting conditions determined under the same conditions for the cutting temperature experiments to be conducted was $5000 \mathrm{rev} / \mathrm{min}$ for the spindle speed, $0.05 \mathrm{~mm} /$ tooth for the feed rate, $5 \mathrm{~mm}$ for the axial depth of cut and $5 \mathrm{~mm}$ for the radial depth of cut.

(3) The value of cutting temperature for the none wave edge tool was $40-80^{\circ} \mathrm{C}$ higher than that for the wave edge tool while the value of cutting temperature for the rake wave edge tool was $40^{\circ} \mathrm{C}$ bigger than that for the flank wave edge tool. However, the wave edge tool was more inclined to taking place severe adhesive wear which attributes to the coarser tool face.

(4) The cutting temperature of CPMJI was $80^{\circ} \mathrm{C}$ lower than that of dry cutting and the situation of severe adhesive wear seldom took place when CPMJI was used compared to dry cutting and cryogenic wind cooling. 


\section{Acknowledgment}

This project was supported by the Nanjing Science and Technology Development Plan (201306024) and Qinglan Project of Jiangsu Province (2014).

\section{References}

[1] G. Campatelli, A. Scippa, Prediction of milling cutting force coefficients for Aluminum 6082-T4, Procedia CIRP 1 (2012) 563-568.

[2] B. Rao and Y.C. Shin, Analysis on high-speed face-milling of 7075-T6 aluminum using carbide and diamond cutters, Int. J. Mach. Tools Manuf. 41 (2001) 1763-1781.

[3] V.D. Calatoru, M. Balazinski, J.R.R. Mayer, H. Paris, G.L. Esperance, Diffusion wear mechanism during high-speed machining of 7475-T7351 aluminum alloy with carbide end mills, Wear 265 (2008) 1793-1800.

[4] C.A.S. Bork, J.F.S. Gonçalves, J.O. Gomes, J. Gheller, Performance of the jatropha vegetable-base soluble cutting oil as a renewable source in the aluminum alloy 7050-T7451 milling, CIRP J. Manuf. Sci. Technol. 7(3) (2014) 210-221.

[5] H.A. Kishawy, M. Dumitrescu, E.G. Ng, M.A. Elbestawi, Effect of coolant strategy on tool performance, chip morphology and surface quality during high-speed machining of A356 aluminum alloy, Int. J. Mach. Tools Manuf. 45 (2005) 219-227.

[6] R. Zitoune, V. Krishnaraj, B.S. Almabouacif, F. Collombet, M. Sima, A. Jolin, Influence of machining parameters and new nano-coated tool on drilling performance of CFRP/Aluminium sandwich, Compos. Part B 43 (2012) 1480-1488.

[7] C. Martini, A. Morri, Face milling of the EN AB-43300 aluminum alloy by PVD- and CVD-coated cemented carbide inserts, Int. J. Refract. Met. Hard Mater. 29 (2011) 662-673.

[8] O. Pecat, R. Rentsch, E. Brinksmeier, Influence of milling process parameters on the surface integrity of CFRP, Procedia CIRP 1 (2012) 466-470.

[9] Y. Karpat, O. Bahtiyar, B. Deger, Milling Force Modelling of Multidirectional Carbon Fiber Reinforced Polymer Laminates, Procedia CIRP 1 (2012) 460-465.

[10] E. Capello, Workpiece damping and its effect on delamination damage in drilling thin composite laminates, J. Mater. Process. Technol. 148 (2004) 186-195.

[11] S. Seguy, G. Dessein, L. Arnaud, Surface roughness variation of thin wall milling, related to modal interactions, Int. J. Mach. Tools Manuf. (3-4) (2008) 261-274.

[12] U. Bravo, O. Altuzarra, L.N.L. Lacalle, J.A. Sanchez, Stability limits of milling considering the flexibility of the workpiece and the machine, Int. J. Mach. Tools Manuf. 45 (2005) 1669-1680.

[13] S. Hannich, T. Brüggemann, M. Tiffe, D. Biermann, A. Zabel, Machining of Lightweight Frame Structures, Procedia CIRP 18 (2014) 84-89. 